Bangladesh J. Plant Taxon. 28(2): 317-328, 2021 (December)

DOI: https://doi.org/10.3329/bjpt.v28i2.57130

(C) 2021 Bangladesh Association of Plant Taxonomists

\title{
SPECIES RELATIONSHIP AND POPULATION DIFFERENTIATION IN STELLARIA L. (CARYOPHYLLACEAE) OF IRAN USING SCOT MOLECULAR MARKER AND MORPHOLOGICAL DATA
}

\author{
${\text { JiALING LI, XiN } \text { YANG }^{1 *} \text { AND Shadi HajRaSOUliha }}^{2}$ \\ College of Engineering Management, Nueva Ecija University of Science and \\ Technology, Cabanatuan, Philippines
}

Keywords: SCoT; morphology; species identification; STRUCTURE; Iran.

\begin{abstract}
Recognition of species is essential in a variety of domains, most remarkably biology, biogeography, ecology, as well as conservation. The genus Stellaria L. (Caryophyllaceae) has over 120 species spread across Europe and Asia's temperate zones. According to the most remarkable current treatments, nine species recognize Stellaria in Iran. These species are categorized into two types. Despite the broad distribution of several Stellaria species in Iran, no research on their genetic variability, method of divergence, or dispersion trends is accessible. As a result, we conducted genetic and morphological research on six Stellaria species and two of their closest relatives gathered from various habitats in Iran. This research aims to 1) Can SCoT markers be utilized to recognize Stellaria species? 2) What are the genetic characteristics of the mentioned taxa in Iran? and 3) To examine the interrelation of the species. In this research, ten SCoT markers were employed for molecular analysis, and 112 accessions were utilized for morphological study. The genetic distances were calculated using the Jaccard similarity coefficient, and descriptive data on the populations were used to estimate genetic parameters. There were 98 polymorphic bands all over. The integration of morphological and SCoT data demonstrated that the Stellaria species of Iran could be delimited and recognized. The Stellaria species are genetically unique; however, they share some similar alleles, according to AMOVA and STRUCTURE analyses.
\end{abstract}

\section{Introduction}

The delimitation of species is significant in various biological fields, including ecology, biogeography, and plant preservation. Species delimitation is accomplished using both tree-based and non-tree-based methods. In the first technique, species are classified into distinct clades depending on synapomorphic traits (phylogenetic species concept); however, in the second method, species could be identified using any taxonomic feature and gene flow evaluations. Wiens and Penkrot (2002) recommended using DNA as well as morphological data for species delimitation. In contrast, Knowles and Carstens (2007) focused on how molecular data (for example, DNA sequence data is utilized to generate gene trees) could be utilized to delimitate species. The former writers utilized coalescent simulations for evaluating the species limitations and combined information from numerous loci. They demonstrated the relevance of population genetics in determining the boundaries of a species.

*Corresponding author, E-mail: smyl1090@ gmail.com; yaaangx@126.com

${ }^{1}$ College of Bioengineering, Chongqing University, Chongqing 400030, China

${ }^{2}$ Department of Development, Faculty of Advanced science and Technology, Tehran Medical Sciences, Islamic Azad University, Tehran, Iran 
Stellaria L. (Caryophyllaceae, Alsinoideae) has around 150-200 species worldwide (Bittrich, 1993). In Iran, nine species in this genus are classified into Stellaria and Pseudalsine. An unclear part exists in S. blatteri Matt., S. scaturiginella Rech.f., and S. sarcophylla Rech. F (Rechinger, 1988). The Stellaria section includes two annual species, S. medium (L.) Vill in Iran.

Stellaria species are widespread plants that favor humid mountainous slopes; however, some have been discovered growing in deserts. The genus is defined by the existence of five sepals and bifid petals; however, certain species have petals that are much reduced or nonexistent (Fior et al., 2006; Harbaugh et al., 2010). Eurasia is the primary breeding ground for Stellaria, with the eastern central Asian highlands acting as a major distribution hub. Additionally, several species are cosmopolitan in their distribution (Bittrich, 1993). There are just a few Stellaria chromosomal records throughout the globe. The genus has been reported to contain basic chromosome numbers $\mathrm{x}=10,11,12$, and 13. Earlier, investigations on the delimitation of species and the linkages between species in this genus have been conducted.

The primary focus of these researches was on the taxonomy, seed, as well as pollen morphology, stem, and leaf anatomy of Stellaria species (Mahdavi et al., 2012; 2014b; EsfandaniBozchaloyi and Keshavarzi, 2014). Verkleij et al. (1980) utilize electrophoretically observable variation in isoenzymes to gain insight into the genetic variations between and within the two species and two local subpopulations of $S$. media.

They demonstrated a variation in the isoenzyme pattern between the species $S$. medium and $S$. pallida for five enzymes. Two of these five enzymes showed interpopulation variation in S. media, and no variability in the isoenzyme structure may be described by the species' persistent autogamous (cleistogamous) condition. There was no indication of polyploidy influencing the isoenzyme pattern of activity. However, no effort has been made to investigate the genetic variation, ecological adaptability, intra-, and inter-specific delineation, and morphometric variation of Stellaria of Iran. There were 112 specimens of two sections of Stellaria collected for morphological and genetic analysis. We point to reply to the taking after questions: 1) Are there infrared and interspecific hereditary differing qualities among the Stellaria species examined? 2) Is there a linkage between genetic and geographical distances among these species? 3) How are populations and taxa genetically structured 4) Does gene exchange occur across Stellaria species in Iran?

\section{Materials and Methods}

\section{Plant materials}

As mentioned in table one, during 2015-2018, 112 plant samples from six Stellaria species of Pseudalsine (S. alsinoides) and Stellaria (S. media, S. pallida, S. holostea, S. persica, and S. graminea) were gathered from natural habitats of Fifteen geographical populations. Several sources were examined to ensure that species were correctly identified (Rechinger, 1988). The sampling sites details are listed (Table 1, Fig. 1). The Herbarium of Azad Islamic University (HAIU) has voucher specimens.

\section{Morphological studies}

Morphometry was conducted on five samples of each species. 24 morphological features (9 qualitative, 15 quantitative) were investigated (Table 2). According to Podani (2000), a Euclidean distance estimate was made for clustering and ordination analysis using the given data, which was standardized $($ Mean $=0$, variance $=1$ ). 


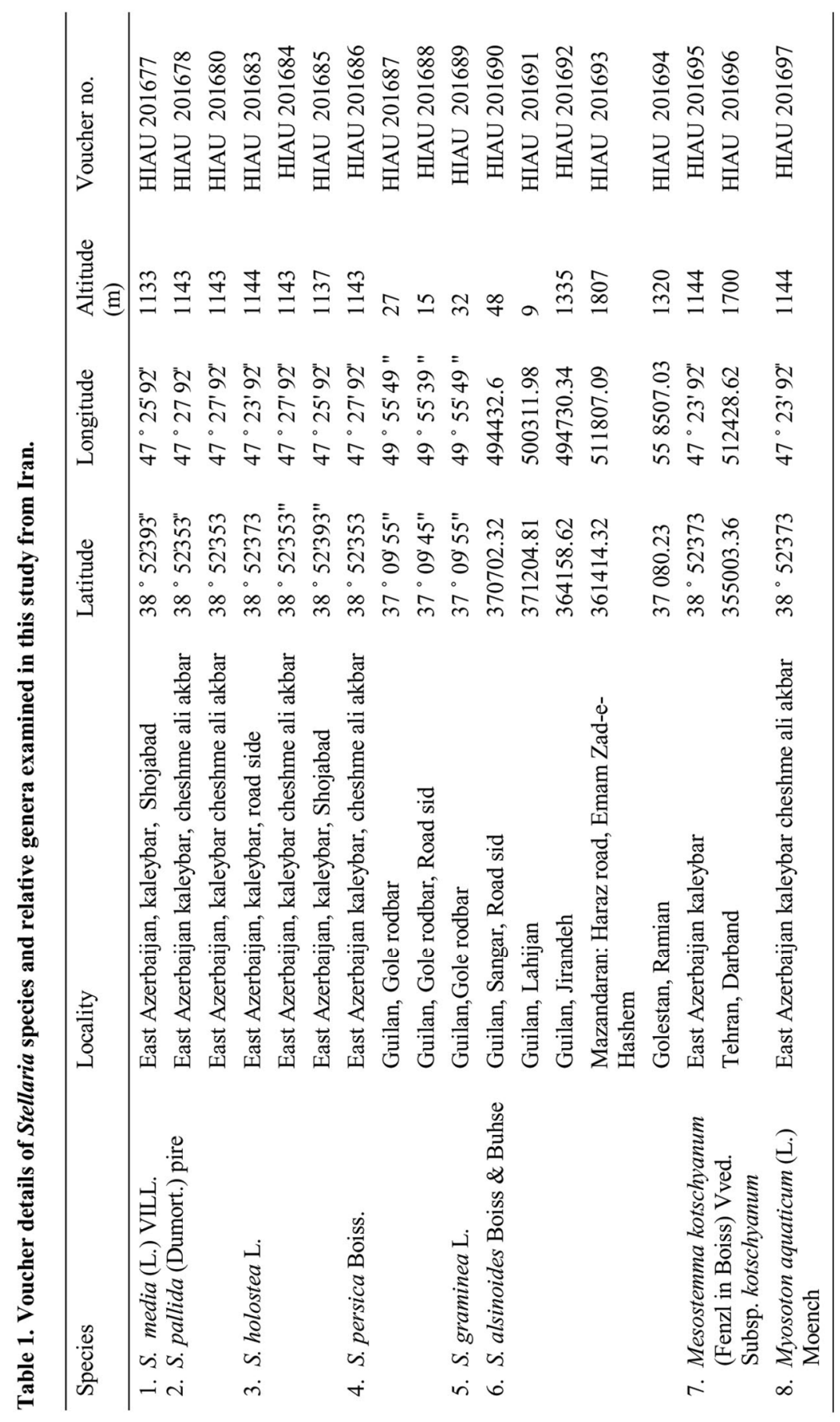




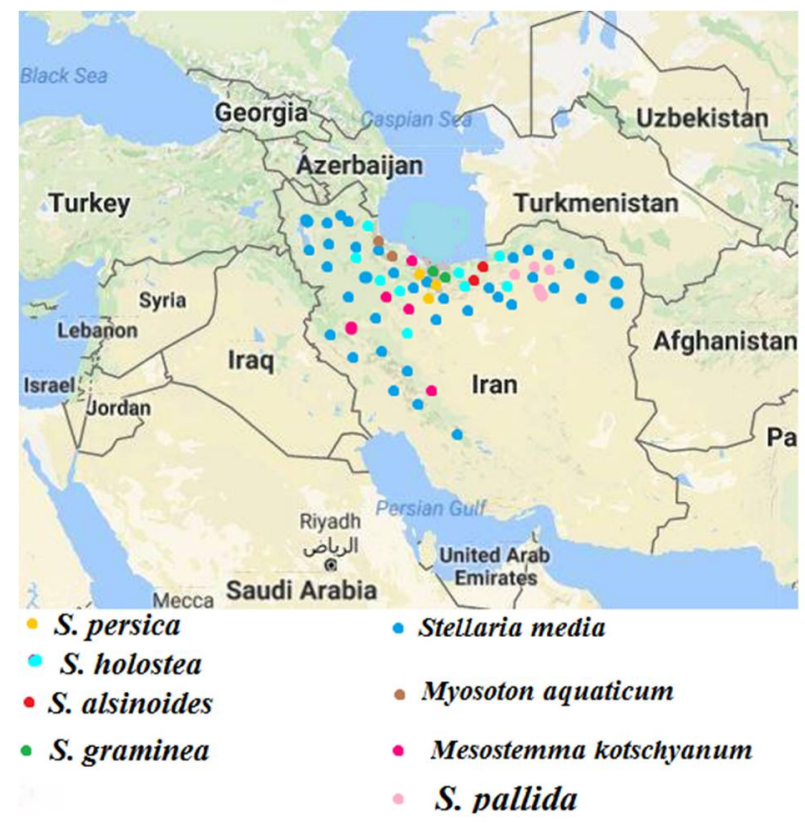

Fig. 1. Distribution map of the studied species of Stellaria.

Table 2. List of selected characters and their codes in morphological studies.

\begin{tabular}{lll}
\hline No. & Characters & Numerical code \\
\hline 1 & Plant height & $\mathrm{mm}$ \\
2 & Length of basal leaves & $\mathrm{mm}$ \\
3 & Width of basal leaves & $\mathrm{mm}$ \\
4 & Length of stem leaves & $\mathrm{mm}$ \\
5 & Width of stem leaves & $\mathrm{mm}$ \\
6 & Bract length & $\mathrm{mm}$ \\
7 & Bract width & $\mathrm{mm}$ \\
8 & Pedicel length & \\
9 & Number of seeds per capsule & \\
10 & Number of flowers per inflorescence & \\
11 & Number of calyx & $\mathrm{mm}$ \\
12 & Calyx length & $\mathrm{mm}$ \\
13 & Calyx width & \\
14 & Number of petal & mm \\
15 & petal length & 0 -annual 1- perennial \\
16 & Growth period & 0 -acute 1- narrow 2- absence \\
17 & Bract apex & 0 -unbranched 1- branched \\
18 & State of stem & 0 -thin 1- strong \\
19 & State of stem strength & 1-unilateral hair 2- multilateral hair \\
20 & Stem hairs & 1- rectangular 2- elliptical \\
21 & Cross-section of stem & 1- linear- lanceolate 2- lanceolate 3- \\
22 & Shape of basal leaves & lanceolate - acuminate 4- ovate \\
& & 0 -acute 1- narrow \\
23 & Basal leaves apex & 0-absence 1- presence \\
24 & Basal leaves petiole & \\
& &
\end{tabular}


Table 3. Genetic diversity parameters in the studied Stellaria species.

\begin{tabular}{llllllll}
\hline Pop & $\mathrm{N}$ & $\mathrm{Na}$ & $\mathrm{Ne}$ & $\mathrm{I}$ & $\mathrm{He}$ & $\mathrm{UHe}$ & $\mathrm{P} \%$ \\
\hline $\mathrm{sp1}$ & 12.000 & 1.347 & 1.404 & 0.381 & 0.174 & 0.182 & $46.91 \%$ \\
$\mathrm{sp} 2$ & 8.000 & 0.429 & 1.097 & 0.084 & 0.056 & 0.060 & $16.13 \%$ \\
$\mathrm{sp} 3$ & 6.000 & 0.258 & 1.029 & 0.023 & 0.016 & 0.010 & $4.38 \%$ \\
sp4 & 12.000 & 0.925 & 1.279 & 0.233 & 0.155 & 0.162 & $22.09 \%$ \\
sp5 & 11.000 & 0.784 & 1.171 & 0.162 & 0.104 & 0.109 & $36.56 \%$ \\
sp6 & 14.000 & 0.344 & 1.039 & 0.014 & 0.021 & 0.023 & $3.98 \%$ \\
sp7 & 14.000 & 0.560 & 1.186 & 0.098 & 0.064 & 0.066 & $21.51 \%$ \\
sp8 & 10.000 & 0.441 & 1.036 & 0.033 & 0.022 & 0.023 & $6.53 \%$ \\
\hline
\end{tabular}

$\mathrm{N}=$ number of samples, $\mathrm{Ne}=$ number of effective alleles, I= Shannon's information index, $\mathrm{He}=$ gene diversity, $\mathrm{UHe}=$ unbiased gene diversity, $\mathrm{P} \%=$ percentage of polymorphism, populations.

\section{DNA extraction and SCoT assay}

Fresh leaves were randomly utilized from 5-10 plants in each group investigated. Silica gel powder was used to dry them. Genomic DNA was extracted using the CTAB activated charcoal technique (Doyle and Doyle, 1987). A 0.8 percent agarose gel was used to test the extracted DNA quality. Collard and Mackill (2009) created 25 SCoT primers; ten primers with distinct, expanded, as well as rich polymorphism bands were selected (Table 3 ). The PCR procedures were conducted in a $25 \mu \mathrm{l}$ volume including ten $\mathrm{mM}$ Tris- $\mathrm{HCl}$ buffer at $\mathrm{pH} 8,50 \mathrm{mM} \mathrm{KCl}, 1.5 \mathrm{mM} \mathrm{MgCl} 2,0.2 \mathrm{mM}$ of every dNTP (Bioron, Germany), $0.2 \mu \mathrm{M}$ of a single primer, $20 \mathrm{ng}$ genomic DNA, as well as $3 \mathrm{U}$ of Taq DNA polymerase (Bioron, Germany). The preceding program was used to execute the amplifications and reactions in a Techne thermocycler (Germany): 5 minutes at $95^{\circ} \mathrm{C}$ for denaturation, accompanied by 37 cycles of 1 minute at $95^{\circ} \mathrm{C}, 1$ minute at $50-56^{\circ} \mathrm{C}$, and 1 minute at $72^{\circ} \mathrm{C}$. A final extension phase of 5-10 minutes at $72^{\circ} \mathrm{C}$ concluded the reaction. The ethidium bromide staining was used to determine the amplification products on a $1 \%$ agarose gel. A $100 \mathrm{bp}$ molecular size ladder was utilized to estimate the fragment size (Fermentas, Germany).

Table 4. Analysis of molecular variance (AMOVA) of the studied species.

\begin{tabular}{lllllll}
\hline Source & df & SS & MS & Est. Var. & $\%$ & $\Phi P T$ \\
\hline Among Pops & 14 & 727.747 & 51.327 & 8.082 & $58 \%$ & \\
\cline { 1 - 5 } Within Pops & 67 & 391.607 & 5.530 & 5.530 & $42 \%$ & \\
\cline { 1 - 5 } Total & 81 & 1119.354 & & 13.612 & $100 \%$ & \\
\cline { 1 - 5 } & & & & &
\end{tabular}

df: degree of freedom; SS: sum of squared observations; MS: mean of squared observations; EV: estimated variance; $\Phi$ PT: proportion of the total genetic variance among individuals within an accession, $(\mathrm{P}<0.001)$.

\section{Data analyses}

Morphological studies: According to Podani (2000), morphological traits were initially standardized $($ Mean = zero, Variance $=1$ ) and employed for calculating Euclidean distance between taxa. The UPGMA (Unweighted paired group using average) method was utilized to group the plant specimens (Podani, 2000). ANOVA (Analysis of Variance) illustrated the morphological variation across populations. At the same time, the PCA (Principal Component Analysis) biplot was employed to discover the most variable morphological features among the analyzed populations (Podani, 2000). Multivariate statistical analyses of morphological data were performed using PAST version 2.17 (Hammer et al., 2012). 
Molecular analyses: The SCoT bands collected were encoded as binary characters (presence $=1$, absence $=0$ ). A variety of parameters were calculated, including Nei's gene diversity $(\mathrm{H})$, the Shannon information index (I), the number of efficient alleles, as well as the polymorphism percentage (Weising et al., 2005; Freeland et al., 2011). Neighbor-Joining (NJ) clustering and Neighbor-Net networking depended on Nei's genetic distance between populations (Freeland et al., 2011; HUSON and BRYANT 2006). The Mantel test was used to determine the association between the analyzed populations' geographical as well as genetic distances (Podani, 2000). These evaluations were carried out using PAST ver. 2.17 (Hammer et al., 2012), DARwin ver. 5 (2012), and SplitsTree4 V4.13.1 (2013) software. The AMOVA (Analysis of Molecular Variance) test (containing 1000 permutations) conducted in GenAlex 6.4 (Peakall and Smouse, 2006) and the Nei,s Gst analysis conducted in GenoDive ver.2 (2013) (Meirmans and Van Tienderen, 2004) were employed to show genetic differentiation across the populations. Furthermore, GST est $=$ standardized measure of genetic differentiation (Hedrick, 2005) and D est $=$ Jost measure of differentiation were used to study population genetic differentiation (JOST, 2008). Bayesian model STRUCTURE analysis and GenoDive ver. 2's maximum likelihood-based K-Means clustering approach (based on maximum likelihood) was used to examine the population's genetic structure (2013). Data were evaluated as dominating markers for STRUCTURE analysis. The admixture ancestry model was utilized with the correlated allele frequency model. The Evanno test was applied to the STRUCTURE result for calculating the appropriate number of $\mathrm{K}$ utilizing the delta K value (Evanno et al., 2005). Two summary statistics, pseudo-F, and Bayesian Information Criterion (BIC), are used to identify the best fit for $\mathrm{k}$ in K-Means clustering (Meirmans, 2012).

Gene flow was calculated by utilizing PopGene ver. 1.32 (1997) to calculate Nm, and gene flow estimate from Gst, as $\mathrm{Nm}=0.5(1-\mathrm{Gst}) / \mathrm{Gst}$. This technique assumes that all populations experience an equal amount of gene flow. (ii) Population assignment test using maximum likelihood, as conducted in GenoDive version 2. (2013), the existence of common alleles was assessed via using DARwin ver 5 to create a ventriculogram network employing the least square approach (2012).

\section{Results and Discussion}

Species identification and inter-relationship

Morphometry: ANOVA revealed significant variations in quantitative morphological features (P 0.01) across the species studied. PCA analysis was used to discover the most variable characteristics among the species investigated. It was discovered that the top three factors accounted for more than $73 \%$ of the overall variation. The parameters length, breadth, hairs, number of sepals, pedicle hair, the width of seed, and capsule form have the strongest correlation $(>0.7)$ in the first PCA axis, accounting for 52 percent of total Variance. The texture of the leaf, the number of stigmas, the number and size of capsule sutures and length, the number of petals, petal existence, as well as stem branching were all factors impacting PCA axis 2 and 3 (figure excluded).

Numerous grouping and ordination techniques yielded the same findings. Figure 2 illustrates a UPGMA grouping and PCA plot of morphological characteristics. Plant samples from each species relating to a specific part were grouped and generated clusters separately in general. This study indicates that the morphological parameters examined could distinguish Stellaria species. We identified no transitional forms among the specimens we investigated.

Generally, the UPGMA tree created two large clusters (Fig. 2). The attributes seed shape, size, quantity per capsule, cauline leaves shape, and several stigmas, the Mesostemma taxa and Myosoton aquaticum created a distinct group in Stellaria in the first cluster. Two sub-clusters were 
included in the second main cluster. Due to morphological similarity, S. media and S. pallida from the Stellaria section and S. alsinoides (Pseudalsine section) formed the first sub-cluster. In contrast, S. persica, S. graminea, and S. holostea (Stellaria section) formed the second sub-cluster. They were distinguished by hair absence, linear, sessile leaves, ten stamens, 3mer stigma, and deeply.

Species identification and genetic diversity

The entire SCoT primers obtained polymorphic bands. According to table two, the genetic variation characteristics evaluated in the examined species indicated that $S$. media (sp1) possessed the greatest amount of genetic polymorphism (46.91 percent), whereas $S$. alsinoides had the lowest level (3.98 percent) (sp6). S. media also exhibited the greatest effective number of alleles $(\mathrm{Ne}=1.4)$ and Shannon information index $(\mathrm{I}=0.38)$ values.

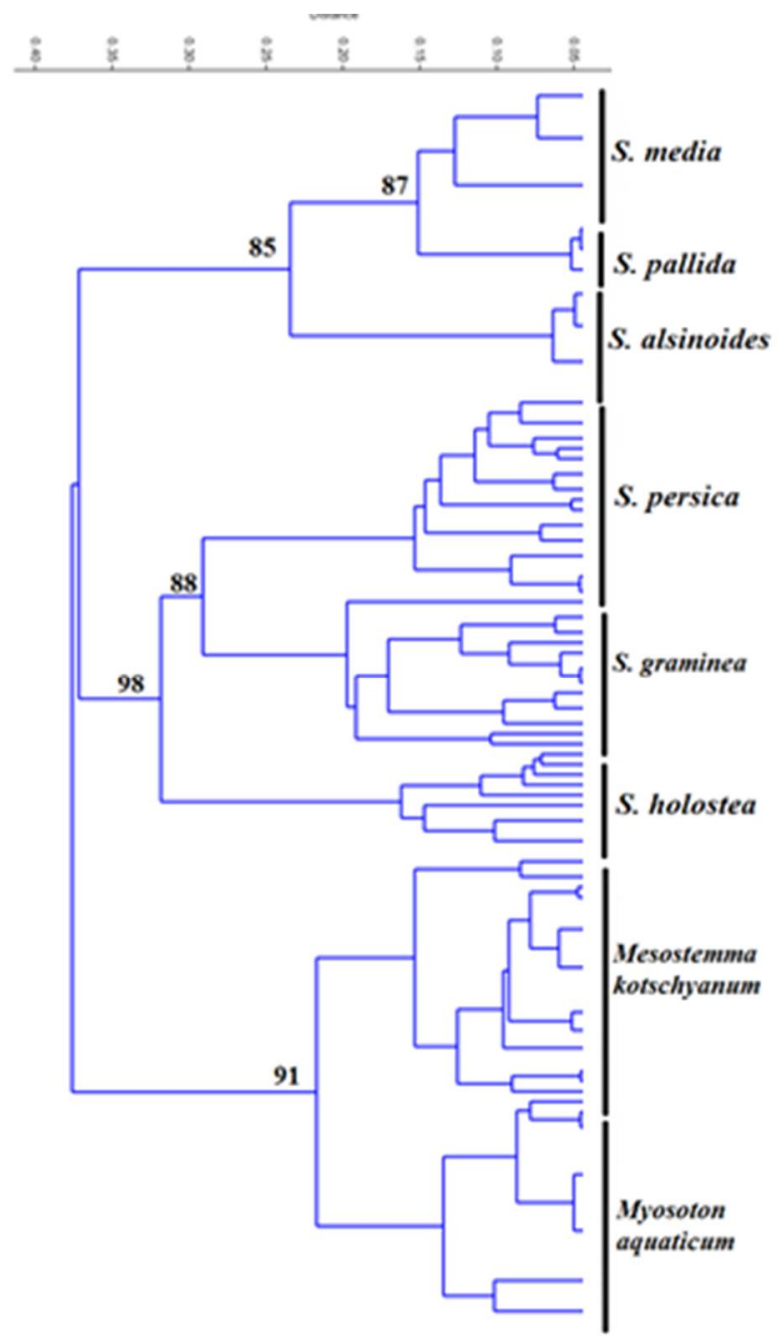

Fig. 2. Species delimitation in the Stellaria revealed by UPGMA clustering of morphological characters. 
The AMOVA test revealed a substantial genetic difference between the examined species $(\mathrm{P}=$ 0.01 ). It demonstrated that $58 \%$ of overall Variance occurred across species, and $42 \%$ occurred within species (Table 4). Furthermore, substantial Nei's GST $(0.41, \mathrm{P}=0.01)$ and D est values $(0.169, \mathrm{P}=0.01)$ were found to indicate genetic divergence between these species.

The NJ tree created using Nei's genetic distance (not included) revealed that Mesostemma taxa and Myosoton aquaticum are genetically distant from the other examined species. This dendrogram revealed that $S$. media and $S$. pallida had a deep genetic affiliation. Likewise, $S$. persica and $S$. graminea (both in the Stellaria section) were positioned close together, with $S$. holostea joining them at a distance. In general, correlations between species derived from SCoT data correlate well with morphological data. This corresponds to AMOVA as well as genetic diversity parameters. The genetic differences between the species are substantial. Additionally, the $\mathrm{Nm}$ study performed by the Popgene program yielded a mean $\mathrm{Nm}=0.23$, which is regarded as a meager amount of gene flow between the analyzed species. The Mantel test containing five hundred permutations revealed a significant association $(r=0.18, p=0.0001)$ between genetic and geographical distance, indicating that isolation by distance (IBD) happened among the Stellaria species tested.

The genetic identification of Nei and the genetic distance between the examined species were established (Table is excluded). These findings indicated that S. media and S. pallida had the greatest degree of genetic similarity (0.90). Between Mesostemma taxa and Myosoton aquaticum, the highest degree of genetic similarity was observed (0.64).

The species genetic structure

We conducted STRUCTURE analysis, followed by the Evanno test to determine the ideal number of genetic groupings. According to pseudo-F and BIC, K-Means clustering yielded $\mathrm{k}=8$ and $\mathrm{k}=14$, respectively. $\mathrm{K}=14$ is consistent with the NJ grouping and AMOVA. $\mathrm{K}=8$ indicates the existence of eight genetic collections. Ployed the admixture model to show interspecific gene flow or/and ancestrally shared alleles. The same result was achieved using the Evanno test on the STRUCTURE analysis, which revealed a significant peak at k $=8$. (Fig. 3).
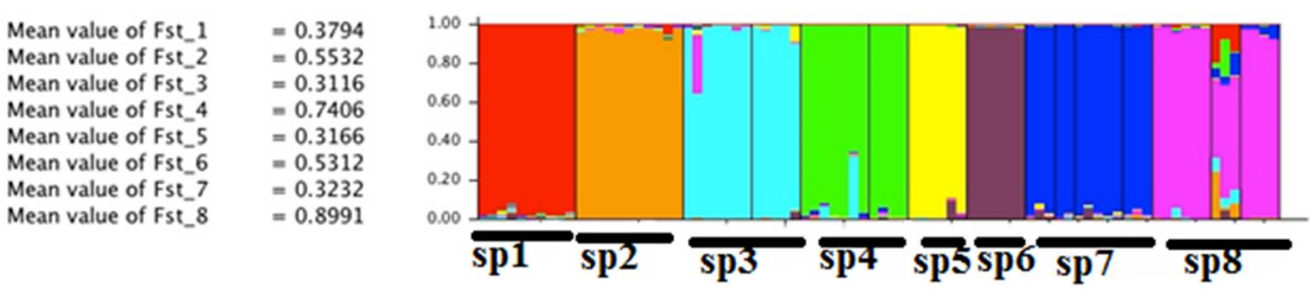

Fig. 3. STRUCTURE plot of Stellaria species based on SCoT data.

The STRUCTURE plot (Fig. 3) revealed further data about the species genetic structure investigated and common ancestral alleles and gene flow among Geranium species. The plot demonstrated the genetic distinction between species 1 and 2 (diversely colored) and between species 7 and 8 . This is consistent with the Neighbor-joining dendrogram that was previously provided. The rest of the species vary in allele composition and are diverse genetically.

The low Nm value (0.23) supports genetic stratification as demonstrated by K-Means and STRUCTURE studies, indicating minimal gene flow or ancestrally shared alleles amongst the species investigated. The population assignment test concurred with the $\mathrm{Nm}$ finding that no evidence of considerable gene flow among the tested species. 


\section{Genetic diversity}

Genetic diversity is a critical component of biological variation for conservation methods (Khayatnezhad, and Gholamin 2021; Gholamin, and Khayatnezhad 2020; 2021; Guo, et al., 2021). The size of the population is thought to be critical for preserving genetic variety. Because of environmental stochasticity, genetic drift, and inbreeding, small people are more prone to extinction than large ones. Genetic drift reduces heterozygosity and eventually allele fixation, but inbreeding enhances homozygosity within populations ( Hou, et al., 2021; Huang, et al., 2021; Jia, et al., 2020; Karasakal, et al., 2020a; 2020b; Khayatnezhad, and Gholamin 2020a; 2020b). Generally, population size declines may result in a loss of genetic diversity due to genetic drift and inbreeding. In the end, reduced genetic variation may decline fitness and the evolutionary potential to respond to environmental alterations (Lande, 1993; Ma, et al., 2021a; 2021b; Peng, et al 2021; Ren, et al, 2021). The conservation and management of small population species rely heavily on characterizing patterns of genetic variability and variation within and across distinct populations.

The current research used SCoT markers to determine the genetic diversity within Stellaria. Our study shows that $S$. alsinoiedes exhibited a reduced amount of genetic diversity (P: 3.98 percent, He: 0.021, I: 0.014). Natural features, reproductive mode, and breeding system have been identified as significant factors influencing genetic diversity levels. Generally, outcrossing species have a far more significant genetic variation than selfing ones (Hamrick and Godt 1989; Nybom 2004). In the past, it was thought that S.'s mating system was mostly self-involved (Peterson, 1936).

Verkleij et al. performed isoenzyme studies on the hypotetraploid $S$. media and the diploid $S$. pallida (1980). Their findings revealed a variation in isoenzyme pattern between the species $S$. medium and $S$. pallida for five enzymes. In $S$. media, two of the five enzymes exhibited interpopulation variation. In $S$. pallida, there was essentially no fluctuation in the isoenzyme pattern that could be described by the species' persistent autogamous (cleistogamous) condition. It was not feasible to demonstrate the effects of polyploidy on the isoenzyme pattern and activity. $S$. medium and S. pallida are primarily self-fertile, and there is a crossing barrier between such species (Peterson, 1936), probably owing to $S$. pallida's diploidy $(2 \mathrm{n}=22)$ and S. media's hypotetraploidy ( $2 \mathrm{n}=40-44)$ (Scholte, 1978). Chinnappa and Morton (1984) used isozyme, RFLP, and RAPD analyses, as well as comparative morphological investigations, to study the genetic variation and phenotypic plasticity that contribute to population divergence within the $S$. longipes complex. Two factors contribute significantly to this species' success: (1) genetic variability resulting from polyploidy, facultative outbreeding, and interspecific gene flow; and (2) the development of phenotypic plasticity because of environmental-induced modifications in the genotypes' physiology and morphological expression. Although all genotypes were selfcompatible, protandrous, gynodioecious, and partly gynodioecious, individuals were prevalent in the species (Philipp, 1975; Chinnappa, 1985). Chinnappa and Morton (1984) confirmed Philipp's (1972) and Chinnappa and Morton's (1984) findings that there is no association between chromosome number and morphology or reproductive biology $(1974,1976)$. Chinnappa and Morton (1991), relying on previous research (Chinnappa and Morton 1974, 1976, 1984; Macdonald et al., 1987), advocated that the Stellaria taxa in issue be classified into an S. longipes complex with two subspecies: S. longipes Goldie subsp. longipes and S. longipes Goldie subsp. arenicola (Raup). The $S$. longipes subsp. arenicola's evolution was thought to have begun with the colonization of a dune environment and a likely change in the breeding system to self-pollination. In its native habitat, $S$. longipes subsp. arenicola is interfertile with other $S$. longipes populations and intergrades, although field investigations show that $S$. longipes subsp. arenicola is predominantly self-pollinating (Macdonald et al., 1987). Otherwise, S. longipes is a single polymorphic species with no well-defined infraspecific taxa (Chinnappa and Morton, 1991). 


\section{Conclusions}

Numerous variables influence the genetic structure, breeding frameworks, hereditary float, populace estimate, and natural selection (Hamrick and Godt, 1990). Our genetic structure analysis revealed that the 112 individuals created a distinct divergence between all groups, a finding that is corroborated by the PCA (Fig. 2). The examination of molecular Variance in all populations uncovered that $58 \%$ of differing hereditary qualities happened over individuals, whereas $42 \%$ occurred inside these bunches (Table 4). The current research concludes that SCoT molecular markers, in conjunction with morphological features, are beneficial for identifying Stellaria species. While there are few interspecific genetic mixing in Stellaria, the examined species are highly distinct throughout the speciation procedure and invasion of new environments.

\section{Acknowledgment}

The authors thank anonymous reviewers for valuable comments on an earlier draft.

\section{References}

Bittrich, V. 1993. Caryophyllaceae. - In: Kubitzki, K., Rohwer, J.G., Bittrich, V. (eds.), The Families and Genera of Vascular Plants, Flowering plants, Dicotyledons, Magnoliid, Hamamelid and Caryophyllid families. Vol. 2, pp. 206-236. Springer-Verlag, Berlin.

Chinnappa, C.C. and Morton, J.K. 1974. The cytology of Stellaria longipes Goldie. Can. J. Genet. Cytol. 16: $499-514$.

Chinnappa, C.C. and Morton, J.K. 1976. Studies on the Stellaria longipes Goldie complex. Variation in wild population. Rhodora. 78: 488-502.

Chinnappa, C.C. and Morton, J.K. 1984.Studies on the Stellaria longipes complex (Caryophyllaceae). Biosyst. Syst. Bot. 9: 60-73.

Chinnappa, C.C. and Morton, J.K. 1991. Studies on the Stellaria longipes complex (Caryophyllaceae) taxonomy. Rhodora. 93: 129-135.

Chinnappa, C.C. 1985a. Studies on Stellaria longipes complex (Caryophyllaceae) interspecific hybridization and triploid meiosis. Can. J. Genet. Cytol. 27: 318-321.

Doyle, J.J. and Doyle, J.L. 1987. A rapid DNA isolation procedure for small quantities of fresh leaf tissue. Phytochemical Bulletin 19: 11-15.

Evanno, G., Regnaut, S. and Goudet, J. 2005. Detecting the number of clusters of individuals using the software STRUCTURE: a simulation study. Molecular Ecology 14: 2611-2620.

Esfandani-Bozchaloyi, S., and Keshavarzi, M. 2014. Micro- and macromorphological study of Stellaria (Caryophyllaceae) and its closest relatives in Iran. Phytologia Balcanica, 20(2): 179-197.

Fior, S., Karis, P.O., Casazza, G., Minuto, L. and Sala, F. 2006. Molecular phylogeny of the Caryophyllaceae (Caryophyllales) inferred from chloroplast $m a t K$ and nuclear rDNA ITS sequences. Amer. J. Bot. 93: 399-411.

Freeland, J.R., Kirk, H. and Peterson, S.D. 2011. Molecular Ecology (2nded). Wiley-Blackwell, UK, 449 pp.

Gholamin, R. and M. Khayatnezhad 2020. "The Study of Path Analysis for Durum Wheat (Triticum durum Desf.) Yield Components." Bioscience Biotechnology Research Communications 13: 2139-2144.

Gholamin, R. and M. Khayatnezhad 2021. "Impacts of PEG-6000-induced Drought Stress on Chlorophyll Content, Relative Water Content (RWC), and RNA Content of Peanut (Arachis hypogaea L.) Roots and Leaves." Bioscience Research 18: 393-402.

Guo, L.-N., C. She, D.-B. Kong, S.-L. Yan, Y.-P. Xu, M. Khayatnezhad And F. Gholinia 2021. "Prediction of the effects of climate change on hydroelectric generation, electricity demand, and emissions of greenhouse gases under climatic scenarios and optimized ANN model." Energy Reports 7: 5431-5445. 
Hou, R., S. Li, M. Wu, G. Ren, W. Gao, M. Khayatnezhad And F. Gholinia 2021. "Assessing of impact climate parameters on the gap between hydropower supply and electricity demand by RCPs scenarios and optimized ANN by the improved Pathfinder (IPF) algorithm." Energy 237: 121621.

Huang, D., J. Wang And M. Khayatnezhad 2021. "Estimation of Actual Evapotranspiration Using Soil Moisture Balance and Remote Sensing." Iranian Journal of Science and Technology, Transactions of Civil Engineering: 1-8.

Harbaugh, D.T., Nepokroeff, M., Rabeler, R.K., Mcneill, J., Zimmer, E.A. and Wagner, W.L. 2010. A new lineagebased tribal classification of the family Caryophyllaceae. - Int. J. Plant Sci. 171: 185-198.

Hammer, O., Harper, D.A. and Ryan, P.D. 2012. PAST: Paleontological Statistics software package for education and data analysis. Palaeonto Electro 4: 9 pp.

Hedrick, P.W. 2005. A standardized genetic differentiation measure. Evolution 59: 1633-1638.

Hamrick, Jl. and Godt, Mjw. 1989. Allozyme diversity in plant species. In: Brown HD, Clegg MT, Kahler AL, eds. Plant population genetics, breeding and genetic resources. Sunderland, MA: Sinauer Associates, Inc., pp. 43-46.

Huson, D.H. and Bryant, D. 2006. Application of Phylogenetic Networks in Evolutionary Studies. Mol. Biol. Evolu. 23: 254-267.

Jost, L. 2008. GST and its relatives do not measure differentiation. Molecular Ecology 17: 4015-4026.

Jia, Y., M. Khayatnezhad and S. Mehri 2020. "Population differentiation and gene flow in Rrodium cicutarium: A potential medicinal plant." Genetika 52: 1127-1144.

Karasakal, A., M. Khayatnezhad and R. Gholamin 2020a. "The Durum Wheat Gene Sequence Response Assessment of Triticum durum for Dehydration Situations Utilizing Different Indicators of Water Deficiency." Bioscience Biotechnology Research Communications 13: 2050-2057.

Karasakal, A., M. Khayatnezhad and R. Gholamin 2020b. "The Effect of Saline, Drought, and Presowing Salt Stress on Nitrate Reductase Activity in Varieties of Eleusine coracana (Gaertn)." Bioscience Biotechnology Research Communications 13: 2087-2091.

Khayatnezhad, M. and R. Gholamin 2020a. "A Modern Equation for Determining the Dry-spell Resistance of Crops to Identify Suitable Seeds for the Breeding Program Using Modified Stress Tolerance Index (MSTI)." Bioscience Biotechnology Research Communications 13: 2114-2117.

Khayatnezhad, M. and R. Gholamin 2020b. "Study of Durum Wheat Genotypes' Response to Drought Stress Conditions." Helix 10: $98-103$

Khayatnezhad, M. and R. Gholamin 2021. "The Effect of Drought Stress on the Superoxide Dismutase and Chlorophyll Content in Durum Wheat Genotypes." Advancements in Life Sciences 8: 119-123.

Keshavarzi, M., and Esfandani -Bozchaloyi, S. 2014a. Leaf and Stem Comparative Anatomical Analysis of Three Genera of Alsinoideae (Caryophyllaceae), Iran. J. Bot. 20(1): 71-79.

Keshavarzi, M. and Esfandani-Bozchaloyi, S. 2014b. Chromosome Numbers For Some Stellaria L. (Caryophyllaceae) Species and Related Taxa In Iran, Iran. J. Bot. 20(1): 36-40.

Knowles, L.L. and Carstens, B. 2007. Delimiting species without monophyletic gene trees. Systematic Biology 56: 887-895. doi:10.1080/10635150701701091.

Lande R. 1993. Risks of population extinction from demographic and environmental stochasticity and random catastrophes. The Amer. Nature. 142: 911-927.

Medrano, M., Lo' Pez-Perea E. and Herrera, C.M. 2014. Population genetics methods applied to a species delimitation problem: Endemic trumpet daffodils (Narcissus section Pseudonarcissi) from the Southern Iberian Peninsula. International Journal of Plant Sciences 175: 501-517. doi: 10.1086/675977

Mayr, E. 1982. The Growth of Biological Thought : Diversity, Evolution, and Inheritance. Cambridge, MA: Harvard University Press. pp. 1-992

Meirmans, P.G. and Van Tienderen, P.H. 2004. GENOTYPE and GENODIVE: two programs for the analysis of genetic diversity of asexual organisms. Molecular Ecology Notes 4: 792-794.

Meirmans, P.G. 2012. AMOVA-based clustering of population genetic data. J. Heredity 103: 744-750. 
Mahdavi, O. M., Assadi, M., Fallahian, F. and Nejadsattari, T. 2012. The systematic significance of seed micromorphology in Stellaria L. (Caryophyllaceae) and its closest relatives in Iran. Iranian J. Bot. 18(2): 302-310.

Macdonald, S.E., Chinnappa, C.C., Reid, D.M. and Purdy, B.G. 1987. Population differentiation of the Stellaria longipes Goldie complex within Saskatchewan's Athabasca sand dunes. Can. J.Bot. 65: 17261732.

Ma, A., J. Ji and M. Khayatnezhad 2021a. "Risk-constrained non-probabilistic scheduling of coordinated power-to-gas conversion facility and natural gas storage in power and gas based energy systems." Sustainable Energy, Grids and Networks: 100478.

Ma, S., M. Khayatnezhad and A. A. Minaeifar 2021b. "Genetic diversity and relationships among Hypericum L. species by ISSR Markers: A high value medicinal plant from Northern of Iran." Caryologia 74: 97 107.

Peng, X., M. Khayatnezhad and L. Ghezeljehmeidan 2021. "Rapd profiling in detecting genetic variation in stellaria 1. (caryophyllaceae)." Genetika-Belgrade 53: 349-362.

Peterson, D. 1935. Some chromosome numbers in the genus Stellaria. Botaniska Notiser 88:409-410.

Philipp, M. 1972. The Stellaria longipes groups in N.W. Greenland. Bot. Tidsskr. 67: 64-75.

Philipp, M. 1975. Flower biology of Stellaria longipes. Bot. Tidsskr. 69: 239-244.

Peakall, R. and Smouse, P.E. 2006. GENALEX 6: genetic analysis in Excel. Population genetic software for teaching and research. Molecular Ecology Notes 6: 288-295.

Podani, J. 2000. Introduction to the Exploration of Multivariate Data English translation. Backhuyes Publisher, Leide, 407 pp.

Pritchard, J.K., Stephens, M. and Donnelly, P. 2000. Inference of population structure using multilocus genotype Data. Genetics 155: 945-959.

Rechinger, K.H. 1988. Stellaria L. In: Rechinger, K.H. (ed.), Flora Iranica. Vol. 163, pp. 60-76. Akad. Druck- und Verlagsanstalt, Graz.

Ren, J. and M. Khayatnezhad 2021. Evaluating the stormwater management model to improve urban water allocation system in drought conditions. Water Supply.

Verkleij, C. De Boer, A.M. and Lugtenborg T.F. 1980. On the Eeogeneties of Stellaria media (L.) Vill. and Stellaria pallida (Dnm.) Pire from Abandoned Arable Field Oecologia (Berl.) 46: 354-359

Wiens, J.J. 2007. Species Delimitation: New approaches for discovering diversity. Systematic. Biology 56: 875-878.

Weising, K., Nybom, H., Wolff, K. and Kahl, G. 2005. DNA Fingerprinting in Plants. Principles, Methods, and Applications. 2nd ed. CRC Press, Boca Rayton, 472 pp.

Wiens, J.J. and Penkrot, T.A. 2002. Delimiting species using DNA and morphological variation and discordant species limitsinspinylizards (Sceloporus). Systematic. Biology 51: 69-91.

(Manuscript received on 2 January 2020; revised on 8 November 2021) 